\title{
Developmental Regulation and Specific Brain Distribution of Phosphorabphilin
}

\author{
Davide L. Foletti and Richard H. Scheller \\ Howard Hughes Medical Institute, Department of Molecular and Cellular Physiology, Stanford University School of \\ Medicine, Stanford, California 94305-5428
}

Protein kinases and phosphatases play an important role in modulating synaptic transmission. The synaptic protein rabphilin associates with synaptic vesicles through the small GTPase Rab3A, binds $\mathrm{Ca}^{2+}$ and phospholipids, and interacts with cytoskeletal elements, yet its function remains controversial. In this study, we have generated phosphospecific antibodies and studied the developmental, subcellular, and brain distribution of rabphilin phosphorylated at serine-234 and serine-274. Our results show that phosphorabphilin is present in vivo under basal conditions in a specific subset of synapses. The phosphorylated rabphilin is abundant in the cerebellum, midbrain,

Synaptic transmission, the main form of cell to cell communication in the nervous system, is triggered by $\mathrm{Ca}^{2+}$ and initiated by synaptic vesicle exocytosis and secretion of neurotransmitters. Many of the proteins that regulate the targeting, docking, priming, and fusion of synaptic vesicles with the plasma membrane have been identified. These proteins belong to families of molecules with homologs that mediate intracellular vesicle transport and include soluble $N$-ethylmaleimide-sensitive factor attachment protein receptors, Sec1-related proteins, Rabs, and Rab-effectors (for review, see Jahn and Südhof, 1999; Lin and Scheller, 2000; Bock et al., 2001). Whereas understanding the function of these proteins will ultimately elucidate the basic machinery of synaptic transmission, studying their modulation will yield insights into some of the mechanisms that control synaptic plasticity and therefore contribute to learning and memory.

Protein phosphorylation is a major mechanism to control protein function. It is therefore not surprising that many of the proteins involved in synaptic transmission have been identified as potential targets of protein kinases (for review, see Turner et al., 1999). Despite a large number of in vitro experiments, our understanding of the in vivo regulation and functional significance of most of these phosphorylation events remains fragmentary. To study the in vivo physiological relevance of phosphosynaptic proteins, we have generated a panel of antibodies that recognize synaptic proteins only in their phosphorylated states. In this report, we describe the results obtained with two phosphospecific antibodies directed against phosphorylated rabphilin. Rabphilin, originally identified on the basis of its GTP-dependent interaction with the small GTPase Rab3A (Shirataki et al., 1993), has been

\footnotetext{
Received March 6, 2001; revised May 11, 2001; accepted May 17, 2001.

We thank Dr. Susan Palmieri for assistance with confocal microscopy and Dr. Susan McConnell and Jeremy Blitzer for critical reading of this manuscript.

Correspondence should be addressed to Richard H. Scheller, Genentech, Inc., 1 DNA Way, South San Francisco, CA 94080-4990. E-mail: scheller@gene.com. Copyright (C) 2001 Society for Neuroscience $0270-6474 / 01 / 215461-12 \$ 15.00 / 0$
}

and medulla; phosphorabphilin is specifically enriched in the climbing fiber synapses of the cerebellar cortex. Its developmental profile reveals a sharp and transient increase at approximately postnatal day 16 , a period critical for the activitydependent pruning of supernumerary climbing fibers in the cerebellum. We propose that the phosphorylation of rabphilin regulates neuronal activity through development and in a synapse-specific manner.

Key words: rabphilin; phosphospecific antibodies; protein kinases; development; climbing fibers; immunohistochemistry

localized to synaptic vesicles (Mizoguchi et al., 1994; Li, 1996), from which it dissociates together with Rab3A during or after exocytosis (Stahl et al., 1996). In addition to Rab3A, several potential interacting molecules have been suggested for rabphilin, including phosphoinositides (Chung et al., 1998), rabaptin 5 (Ohya et al., 1998), $\alpha$-actinin (Kato et al., 1996), and $\beta$-adducin (Miyazaki et al., 1994). Whereas these multiple binding partners have implicated rabphilin in exocytosis, endocytosis, and in interactions with the cytoskeleton, its true function remains controversial. In fact, overexpression of full-length rabphilin stimulated exocytosis in pheochromocytoma 12 (PC12) cells, chromaffin cells, and pancreatic $\beta$ cells (Chung et al., 1995; Komuro et al., 1996; Arribas et al., 1997), but its microinjection inhibited neurotransmitter release in squid nerve terminals (Burns et al., 1998). Furthermore, the rabphilin knock-out (KO) displayed no obvious impairments in synaptic transmission (Schluter et al., 1999). Phosphorylation of rabphilin occurs within its central domain on serine-234 primarily by protein kinase A (PKA) and on serine-274 mainly by $\mathrm{Ca}^{2+} /$ calmodulin kinase II (CaMKII) (Fykse et al., 1995). Studies with hippocampal synaptosomes and cultured cerebellar granule cells have indicated that rabphilin can be phosphorylated in vivo in a stimulationdependent manner (Fykse, 1998; Lonart and Südhof, 1998). In this report, we have analyzed the individual contributions of the two phosphorylation sites on rabphilin. We have identified the regions of the brain that have high levels of phosphorabphilin, localized it to a specific subset of synapses, and observed a striking developmental regulation of this modification.

\section{MATERIALS AND METHODS}

Antibodies and reagents. The mouse monoclonal antibodies used in this study were: anti-rabphilin from Transduction Laboratories (Lexington, KY), anti-synaptophysin from Boehringer Mannheim (Indianapolis, IN), anti-calbindin from Swant (Bellinzona, Switzerland), and anti-Rab3a from Synaptic Systems (Goettingen, Germany). The nuclear marker Toto-3 was purchased from Molecular Probes (Eugene, OR). Secondary 
antibodies for immunostaining were from Jackson ImmunoResearch (West Grove, PA) and included fluorescein isothiocyanate-conjugated AffiniPure goat anti-rabbit IgG and Texas Red-conjugated AffiniPure goat anti-mouse IgG. Secondary antibodies for quantitative Western blot analysis were obtained from Amersham Pharmacia Biotech (Arlington, $\mathrm{IL})$ and included anti-rabbit Ig from donkey ${ }^{125} \mathrm{I}$-labeled $\mathrm{F}\left(\mathrm{ab}^{\prime}\right)_{2}$ fragment] and anti-mouse Ig from sheep [ ${ }^{125}$ I-labeled $\mathrm{F}\left(\mathrm{ab}^{\prime}\right)_{2}$ fragment]. Casein kinase II (CKII; recombinant from Escherichia coli), PKA (catalytic subunit), and protein kinase $\mathrm{C}$ (PKC) were from Boehringer Mannheim (Indianapolis, IN). CaMKII and Microcystin-LR were from Calbiochem (La Jolla, CA). Calf intestinal alkaline phosphatase (CIP) was from New England Biolabs (Beverly, MA). Paraformaldehyde was from Electron Microscopy Sciences (Fort Washington, PA). Unless otherwise stated, all other reagents were obtained from Sigma (St. Louis, MO) or Fisher Biotech (Pittsburgh, PA).

Generation and purification of $\alpha S 234-P$ and $\alpha S 274-P$. Two peptides corresponding to amino acids 230-239 (TRRASEARMS) and 270-279 (RRANSVQASR) of rabphilin (Li et al., 1994; Fykse et al., 1995) were synthesized with a phosphoserine at position 234 or 274, respectively. An additional cysteine residue was introduced at the $\mathrm{C}$ terminus for coupling purposes. The peptides were coupled to Imject maleimide-activated keyhole limpet hemocyanin (Pierce, Rockford, IL) and used as immunogen in rabbit. The polyclonal antisera were affinity purified as follows. A peptide with unrelated sequence, a peptide with the same sequence but with unphosphorylated serine (related nonphosphopeptide), and the peptide used as immunogen (phosphopeptide) were coupled to Imject maleimide-activated bovine serum albumin (BSA; Pierce). The conjugates were then linked to cyanogen bromide-activated Sepharose 4B (Sigma). The polyclonal antisera were first sequentially passed over columns carrying the peptide with unrelated sequence and the related nonphosphopeptide to remove nonspecific antibodies. Finally, the antisera were affinity purified by binding and elution from a column carrying the phosphopeptide.

Recombinant proteins and in vitro phosphorylation. A recombinant fragment of rat rabphilin encompassing amino acids 1-361 [wild-type (WT); a gift from Dr. Südhof, University of Texas Southwestern Medical Center, Dallas, TX] as well as single serine to alanine mutants at the phosphorylation sites (S234A and S274A) were expressed and purified as described ( $\mathrm{Li}$ et al., 1994). The mutants were generated by PCRmediated site-directed mutagenesis, and the mutations were confirmed by automated DNA sequencing. The recombinant protein syn1A11 [rat syntaxin 1A, amino acid (aa) 4-266] was expressed and purified as described (Yang et al., 1999). Recombinant rabphilin (WT, S234 and S274) was in vitro phosphorylated by PKA, PKC, and CaMKII under the following conditions. For PKA: $50 \mathrm{~mm}$ MES-NAOH, pH 6.9, $10 \mathrm{~mm}$ $\mathrm{MgCl}_{2}, 0.5 \mathrm{~mm}$ EDTA, $1.0 \mathrm{~mm}$ DTT, $200 \mu \mathrm{M}$ ATP, and $10^{-4} \mathrm{U}$ of PKA per 20 pmol of protein. For PKC: $50 \mathrm{~mm}$ Tris-HCl, pH 7.5, $6 \mathrm{~mm} \mathrm{MgCl}_{2}$, $0.1 \% \beta$-mercaptoethanol, $100 \mu \mathrm{M} \mathrm{CaCl}_{2}, 100 \mathrm{nM}$ PMA, $200 \mu \mathrm{M}$ ATP, and $10^{-4} \mathrm{U}$ of PKC per $20 \mathrm{pmol}$ of protein. For CaMKII: $50 \mathrm{~mm}$

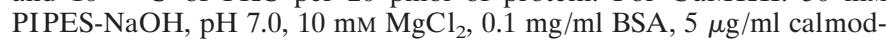
ulin, $500 \mu \mathrm{M} \mathrm{CaCl}_{2}, 200 \mu \mathrm{M} \mathrm{ATP}$, and $25 \mathrm{ng}$ of CaMKII. In vitro phosphorylation of recombinant syn1A11 by CKII was achieved in $50 \mathrm{~mm}$ Tris- $\mathrm{HCl}, \mathrm{pH}$ 7.4, $130 \mathrm{~mm} \mathrm{KCl}, 10 \mathrm{~mm} \mathrm{MgCl}_{2}, 1 \mathrm{~mm}$ DTT, $30 \mu \mathrm{M}$ D-Sphingosine, $200 \mu \mathrm{M}$ ATP, and $10^{-4} \mathrm{U}$ of casein kinase II per $20 \mathrm{pmol}$ of protein. The phosphorylation reactions were incubated for $30 \mathrm{~min}$ at $30^{\circ} \mathrm{C}$ and stopped by addition of SDS-PAGE sample buffer. In Western blot experiments, equal amounts of total protein for each sample were resolved by SDS-PAGE and transferred to nitrocellulose membranes (Hybond ECL; Amersham Pharmacia Biotech, Piscataway, NJ) according to standard protocols. Western blots were analyzed by phosphorimaging technology (Molecular Dynamics, Sunnyvale, CA).

Rat brain fractionation. Total rat brain or dissected rat brain parts were homogenized with a glass-Teflon homogenizer in the presence of phosphatase inhibitors. The buffer used was composed of $20 \mathrm{~mm}$ HEPES$\mathrm{NaOH}, \mathrm{pH} 7.4,200 \mathrm{~mm} \mathrm{NaCl}, 1 \mathrm{~mm}$ DTT, $2 \mathrm{~mm}$ EDTA, $20 \mathrm{~mm}$ $\beta$-glycerophosphate, $50 \mathrm{~mm} \mathrm{NaF}, 50 \mathrm{~mm}$ Na-pyrophosphate, $2 \mu \mathrm{M}$ Microcystin-LR, $2 \mu \mathrm{g} / \mathrm{ml}$ aprotinin, $2 \mu \mathrm{g} / \mathrm{ml}$ leupeptin, $0.7 \mu \mathrm{g} / \mathrm{ml}$ pepstatin, and $1 \mathrm{~mm}$ PMSF. For the preparation of the homogenate in the absence of phosphatase inhibitors, the following reagents were omitted: $\beta$-glycerophosphate, NaF, Na-pyrophosphate, Microcystin-LR; additionally the homogenate was incubated for $30 \mathrm{~min}$ with $50 \mathrm{U}$ of CIP. For subfractionation into cytosol and membranes, the homogenate was first centrifuged at $1000 \times g$ for $15 \mathrm{~min}$. The resulting postnuclear supernatant was further centrifuged at $100,000 \times g$ for $1 \mathrm{hr}$ to separate the cytosolic fraction (supernatant) from the membrane fraction (pellet).
Homogenates were extracted with $1 \%$ Triton X-100 for $1 \mathrm{hr}$ at $4^{\circ} \mathrm{C}$ and then spun at $100,000 \times g$ for $1 \mathrm{hr}$ to pellet the insoluble fraction. The supernatants containing the solubilized proteins were used for Western blotting.

Hippocampal cultures and immunostaining. Primary cultures of hippocampal neurons were prepared from the hippocampi of 18-d-old fetal rats as described previously (Banker and Cowan 1977; Hazuka et al., 1999). For immunocytochemistry experiments, cells were fixed in $4 \%$ formaldehyde and $120 \mathrm{~mm}$ sucrose in PBS for $20 \mathrm{~min}$ at room temperature (RT). After quenching the formaldehyde with $0.1 \mathrm{M}$ glycine in PBS, cells were permeabilized, and nonspecific sites were blocked in PBS containing $0.4 \%$ saponin, $2 \%$ normal goat serum, and $1 \%$ bovine serum albumin (permeabilization/blocking buffer). Primary antibodies, diluted in permeabilization/blocking buffer, were applied for $1 \mathrm{hr}$ at RT. After rinsing the cells five times for $5 \mathrm{~min}$ with PBS, secondary antibodies were applied for $1 \mathrm{hr}$ at RT. Finally, cells were washed five times for $5 \mathrm{~min}$ and mounted onto slides with Vectashield (Vector Laboratories, Burlingame, CA) as mounting medium. For immunohistochemistry experiments on rat brain sections, postnatal day $8(\mathrm{P} 8)$ and adult rats were anesthetized with an intraperitoneal injection of Nembutal and then sequentially perfused intracardially with ice-cold $0.1 \mathrm{M}$ phosphate buffer and $4 \%$ ice-cold formaldehyde in $0.1 \mathrm{M}$ phosphate buffer. The brains were then removed from the skull, post-fixed in the same fixative for $2-4 \mathrm{hr}$ on ice, and finally cryoprotected by immersion in $20 \%$ sucrose for $24 \mathrm{hr}$. Frozen brains were cut with a cryostat, generating $16-\mu \mathrm{m}$-thick sagittal sections that were mounted on glass slides. The staining protocol was performed at room temperature. The sections were first air-dried for $15 \mathrm{~min}$ and then permeabilized for 1-2 $\mathrm{hr}$ (this step also served to block nonspecific binding sites) in permeabilization/blocking buffer. Primary antibodies diluted in permeabilization/blocking buffer were applied to the sections for $4 \mathrm{hr}$ in a humidified chamber. After washing the sections five times for 5 min with permeabilization/blocking buffer, secondary antibodies were applied for 1-2 hr. Finally, the sections were rinsed as above and mounted with Vectashield as mounting medium. Microscopy was performed with a Molecular Dynamics laser confocal imaging system (Stanford University, Cell Sciences Imaging Facility).

\section{RESULTS}

\section{Antibodies specific to the serine-234 and serine-274 phosphorylated forms of rabphilin}

To characterize the occurrence and begin to understand the functional significance of the phosphorylation of rabphilin, we have generated and purified two polyclonal antibodies that recognize rabphilin only when the serines at position 234 and 274 are phosphorylated ( $\alpha \mathrm{S} 234-\mathrm{P}$ and $\alpha \mathrm{S} 274-\mathrm{P}$, respectively). Peptides encompassing the phosphorylation sites were synthesized in which the relevant serine residue was included as a phosphoserine (Fig. 1A). The peptides were coupled to keyhole limpet hemocyanin and used as immunogens in rabbits. The polyclonal antisera were affinity purified by sequential passage through columns carrying a peptide with unrelated sequence and a related non-phosphopeptide (with the same sequence as the peptide used for immunization) to remove nonspecific antibodies. Finally, the antisera were affinity purified by specific binding and elution to the phosphopeptide originally used as the immunogen.

Figure $1 B-D$ illustrates the specificity of the two antibodies. A recombinant fragment of wild-type rabphilin (WT; aa 1-361), as well as serine to alanine mutants at the two phosphorylation sites of the same fragment (S234A and S274A, respectively) were used as substrates for in vitro phosphorylation with CaMKII, cAMP-dependent PKA, and PKC. Recombinant syntaxin $1 \mathrm{~A}$ was phosphorylated in vitro with CKII, resulting in a stoichiometric phosphorylation on serine-14 (Foletti et al., 2000). Equal amounts of in vitro phosphorylated recombinant syntaxin $1 \mathrm{~A}$, wild-type, and mutant rabphilin and unphosphorylated rabphilin were resolved by SDS-PAGE and transferred to nitrocellulose. The blots were probed with $\alpha \mathrm{S} 234-\mathrm{P}$ (Fig. $1 B$ ) and $\alpha \mathrm{S} 274-\mathrm{P}$ (Fig. $1 C$ ) to confirm the spec- 

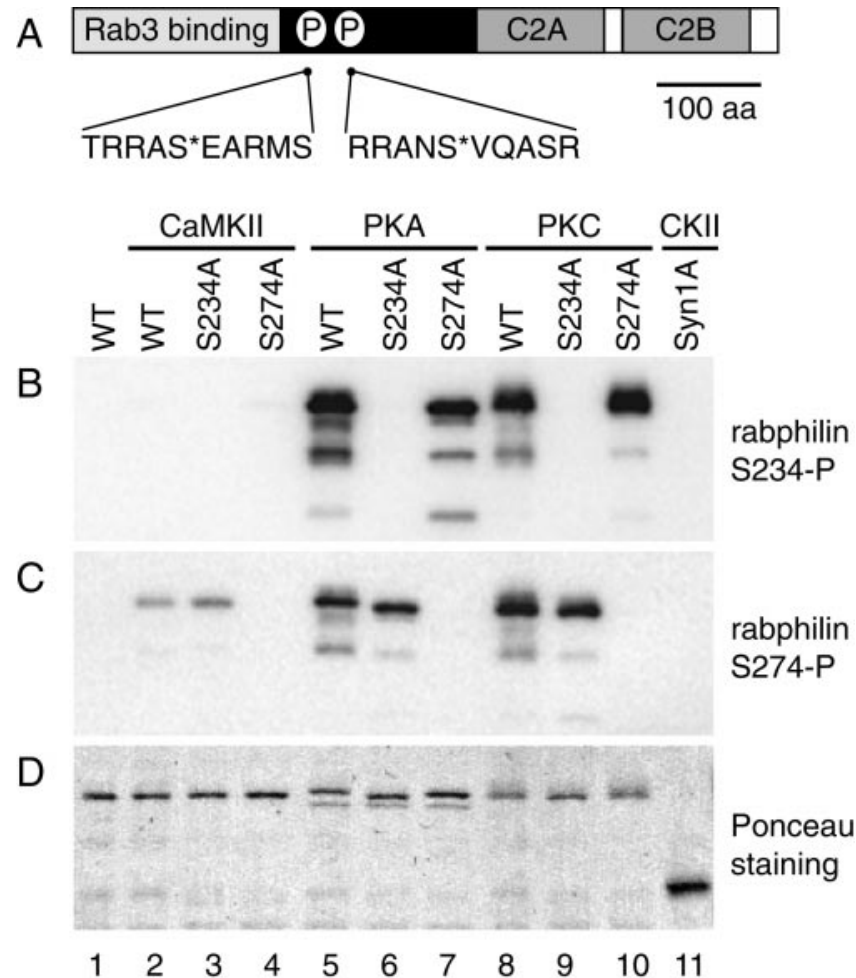

Figure 1. The $\alpha \mathrm{S} 234-\mathrm{P}$ and $\alpha \mathrm{S} 274-\mathrm{P}$ antibodies are specific for the respective phosphorylated forms of rabphilin. $A$, Diagram of the domain structure of rabphilin. The $\mathrm{N}$-terminal domain is cysteine-rich, binds $\mathrm{Zn}^{2+}$, and is responsible for the interaction with Rab3. The C-terminal domain contains two $\mathrm{C} 2$ domains $(\mathrm{C} 2 \mathrm{~A}$ and $\mathrm{C} 2 \mathrm{~B})$. The phosphorylation sites at serine-234 and serine-274 are indicated by the letter $P$. The corresponding sequence of the phosphopeptides used as immunogens is listed below the diagram, $S *$ indicates the phosphoserine. $B-D$, A recombinant fragment of rabphilin containing the two phosphorylation sites at S234 and S274 (WT, aa 1-361) as well as single serine to alanine mutants at the phosphorylation sites of the same fragment (S234A, S274A), were in vitro phosphorylated with the indicated kinases. In lane 1 the recombinant rabphilin was not phosphorylated, and in lane 11 recombinant syntaxin 1A was phosphorylated at serine-14 with casein kinase II. One hundred and fifty nanograms of recombinant rabphilin and $500 \mathrm{ng}$ of recombinant syntaxin were resolved by SDS-PAGE, transferred to nitrocellulose, and probed with the $\alpha \mathrm{S} 234-\mathrm{P}$ and $\alpha \mathrm{S} 274-\mathrm{P}$ antibodies in $B$ and $C$, respectively. In $D$, the Ponceau staining shows that equal amounts of protein were loaded in each lane. Neither antibody recognizes the unphosphorylated rabphilin $(B, C$, lane 1$)$ or the phosphoserine present on syntaxin $1 \mathrm{~A}(B, C$, lane 11$)$. $\alpha \mathrm{S} 234-\mathrm{P}$ recognizes the WT and the S274A mutant recombinant rabphilin phosphorylated by PKA (B, lanes 5 and 7 ) and PKC (B, lanes 8 and 10$)$. A point mutation at S234 completely abolishes this signal (B, lanes 6 and 9). Similarly, $\alpha$ S274-P recognizes the WT and the S234A mutant recombinant rabphilin phosphorylated by CaMKII ( $C$, lanes 2 and 3$)$, PKA $(C$, lanes 5 and 6$)$, and PKC $(C$, lanes 8 and 9$)$. A point mutation at S274 completely abolishes this signal $(C$, lanes 7 and 10).

ificity of the two antibodies. The Ponceau staining in Figure $1 D$ shows that an equivalent amount of proteins was loaded in each lane. Neither of the antibodies recognized the unphosphorylated wild-type protein (Fig. $1 B, C$, lane 1), nor did they cross-react with another phosphoserine-containing protein (syntaxin 1A phosphorylated on serine-14) (Fig. 1B,C, lane 11). $\alpha \mathrm{S} 234-\mathrm{P}$ is specific for rabphilin phosphorylated at serine234: the antibody strongly detected WT rabphilin phosphorylated by PKA and PKC (Fig. 1B, lanes 5 and 8 ), and the signal was abolished when the S234A mutant was used in the phos- phorylation reaction (Fig. $1 B$, lanes 6 and 9). As expected, the S274A mutant phosphorylated by PKA and PKC was also recognized by $\alpha$ S234-P (Fig. 1B, lanes 7 and 10). Under our in vitro phosphorylation conditions, PKA and PKC, but not CaMKII, phosphorylated rabphilin at S234 equally well. Similarly, $\alpha \mathrm{S} 274-\mathrm{P}$ is specific for rabphilin phosphorylated at serine-274: the antibody detected both wild-type and the S234A mutant phosphorylated by CaMKII, PKA, and PKC (Fig. 1C, lanes 2-3, 5-6, and 8-9, respectively). The signal was abolished when the S274A mutant was used in the phosphorylation reaction (Fig. 1C, lanes 4, 7, and 10). Under our in vitro phosphorylation conditions, rabphilin was efficiently phosphorylated at serine-274 by PKA and PKC and weakly by CaMKII. Our phosphorylation results with recombinant rabphilin and purified kinases are consistent with previously reported in vitro experiments. Serine-234 was identified as the major phosphorylation site for PKA, and CaMKII was suggested to phosphorylate both serine-234 and serine-274, with the second serine being the preferential site (Fykse et al., 1995). Our experiments also clearly show, for the first time, that both serine-234 and serine-274 can be efficiently phosphorylated by PKC in vitro.

\section{Phosphorabphilin is particularly abundant in the cerebellum, medulla, and midbrain}

Having established the specificity of $\alpha \mathrm{S} 234-\mathrm{P}$ and $\alpha \mathrm{S} 274-\mathrm{P}$ to in vitro-phosphorylated recombinant rabphilin, we then investigated the in vivo occurrence of the two phosphorylations and the specificity of the two antibodies against native full-length rabphilin in the context of total rat brain homogenate. Rat brains were homogenized in the presence (PI) or absence of phosphatase inhibitors, and the homogenate prepared in the absence of phosphatase inhibitors was additionally treated with CIP. The two samples were subjected to Western blotting and probed with an antibody against total rabphilin ( $\alpha$ total rabphilin; this antibody recognizes the protein irrespective of its phosphorylation state) and the two phosphospecific antibodies $\alpha$ S234-P and $\alpha$ S274-P. The entire gel of the Western blot is shown in Figure $2 A$. Total rabphilin was equally recognized as a protein of $\sim 86 \mathrm{kDa}$ in the homogenates prepared in the presence and absence of phosphatase inhibitors (PI and CIP, respectively) (Fig. 2A, lanes 1 and 2). Both $\alpha$ S234-P and $\alpha$ S274-P detected a protein whose mobility matched that of rabphilin in the homogenate prepared in the presence of phosphatase inhibitors (Fig. 2A, lanes 3 and 5). Absence of phosphatase inhibitors and CIP treatment completely abolished the signal (Fig. 2A, lanes 4 and 6 ), and no other cross-reacting bands were detected over a molecular weight range of $\sim 15$ to $\sim 220 \mathrm{kDa}$, further confirming the specificity of the two antibodies.

After detecting phosphorabphilin in a total rat brain homogenate, we sought to determine which regions of the rat brain, if any, were particularly enriched for the phosphorylated forms of the protein. Equal amounts of total protein from the olfactory bulb (OB), cortex (CTX), hippocampus (HC), midbrain (MB), medulla (ME), cerebellum (CB), and spinal cord (SC) were resolved by SDS-PAGE and transferred to nitrocellulose. The blots were probed with $\alpha$ S234-P, $\alpha$ S274-P, and $\alpha$ total rabphilin. Total rabphilin was present in similar amounts in all areas of the brain tested (Fig. 2B, bottom panel). In contrast, rabphilin phosphorylated at both serine-234 (Fig. 2B, top panel) and serine-274 (Fig. $2 B$, middle panel) was strongly detected in the cerebellum, medulla, and midbrain, with only fainter signals in the other regions 
A
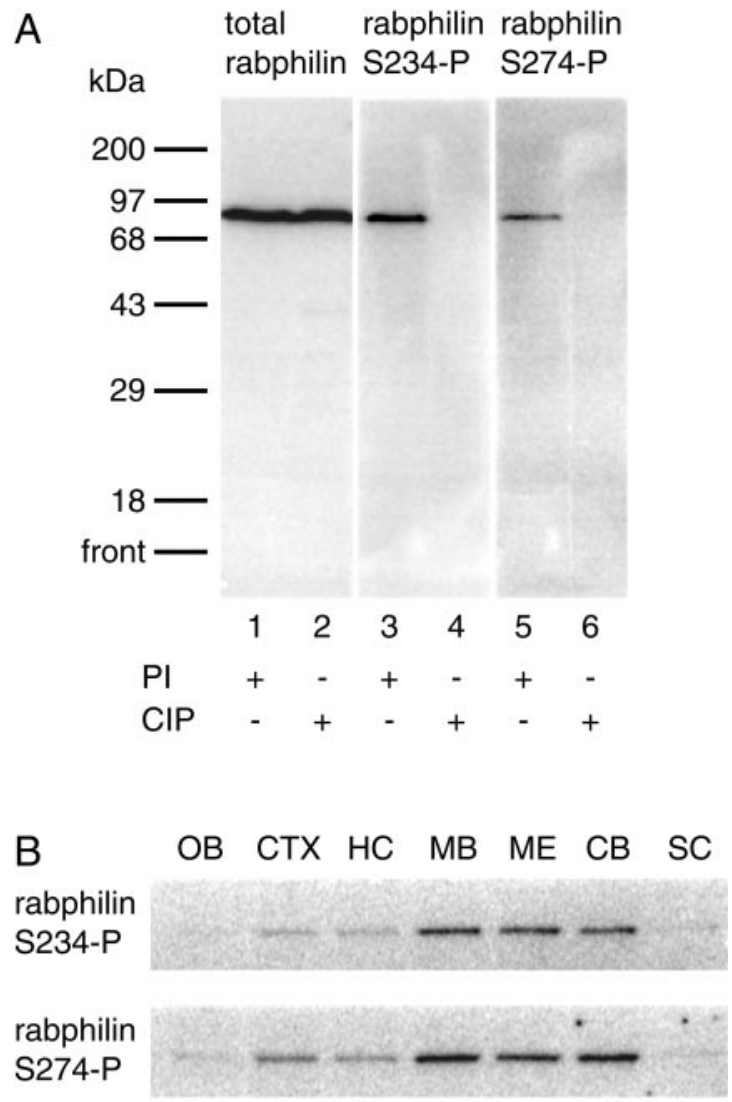

total rabphilin

Figure 2. Phosphorylated rabphilin is abundant in the midbrain, medulla, and cerebellum. $A$, Rat brain homogenates were prepared in the presence $(P I)$ or absence of phosphatase inhibitors. Homogenates prepared in the absence of PI were additionally treated with calf intestinal phosphatase $(C I P)$. Two hundred micrograms of total protein was resolved by SDS-PAGE, transferred to nitrocellulose, and probed with a commercial antibody against rabphilin (total rabphilin, lanes 1 and 2), as well as the $\alpha \mathrm{S} 234-\mathrm{P}$ and $\alpha \mathrm{S} 274-\mathrm{P}$ antibodies (lanes 3-4 and 5-6, respectively). The total rabphilin antibody recognizes rabphilin as a single band of $\sim 86 \mathrm{kDa}$ in both PI- and CIP-treated samples (lanes 1 and 2). $\alpha \mathrm{S} 234-\mathrm{P}$ and $\alpha$ S274-P detects a single band with the same molecular weight only from homogenates prepared in the presence of phosphatase inhibitors (lanes 3 and 5, respectively). The absence of phosphatase inhibitors and the additional treatment with CIP completely abolishes the signal, further confirming the phosphospecificity of the antibodies (lanes 4 and 6 ). $B$, An adult rat brain was dissected into olfactory bulb $(O B)$, cortex $(C T X)$, hippocampus $(H C)$, midbrain $(M B)$, medulla $(M E)$, cerebellum $(C B)$, and spinal cord $(S C)$. The tissues were homogenized in the presence of phosphatase inhibitors and extracted with Triton X-100. Fifty micrograms of total protein from each sample was resolved by SDS-PAGE, transferred to nitrocellulose, and probed for total rabphilin (bottom panel), as well as for its phosphorylated forms using the $\alpha$ S234-P and $\alpha$ S274-P antibodies (top and middle panels, respectively). Although total rabphilin is present in similar amounts throughout the regions tested, both phosphorylated forms of rabphilin are particularly enriched in midbrain, medulla, and cerebellum.

of the brain. These results clearly show that rabphilin phosphorylated at both serine-234 and serine-274 is present in vivo in the rat brain under basal, unstimulated conditions. The data also indicate that the phosphorylation of rabphilin is differentially regulated in distinct anatomical regions of the brain. Finally, the identical distribution of the two phosphorylated forms of rabphi- lin suggests that the regulation and functional significance of the two phosphorylation sites may be linked.

\section{Phosphorabphilin is transiently upregulated during development}

Because we have detected phosphorabphilin in the brain of adult rats under basal, unstimulated conditions, we investigated whether the phosphorylation of rabphilin is developmentally regulated. We analyzed the relative developmental profiles of total rabphilin compared with both forms of phosphorabphilin in rat brains and in the absence of Rab3a in brains obtained from Rab3a knock-out animals. First, the brains from rats of various ages, from embryonic day 18 through development into adulthood, were collected and processed for Western blotting. The blots were probed for total rabphilin (Fig. 3A, open squares), rabphilin S234-P (Fig. 3B, open squares), and rabphilin S274-P (Fig. 3C, open squares). The amount of synaptic proteins increases steadily during development and reaches a plateau around the third week after birth (Foletti et al., 2000). As shown in Figure $3 \mathrm{~A}$ (open squares), rat total rabphilin follows this pattern. In contrast, the presence of both forms of rat phosphorabphilin during development is marked by a sharp increase starting at postnatal day 10 , peaking at day 16, and quickly declining afterwards (Fig. 3B, $C$, open squares). As observed for the distribution in the different regions of the rat brain, the two phosphorylated forms of rabphilin behave similarly during development. This further suggests that the phosphorylation of the two serines may be regulated together and that both phosphorylation events are implicated in modifying the function of the protein.

Considering the reported interaction between Rab3a and rabphilin, we next compared the developmental regulation of phosphorabphilin in wild-type and Rab3a knock-out mice. In the Rab3a knock-out mice, the amount of rabphilin present in the brain is reduced to $\sim 40-50 \%$ of wild type (Geppert et al., 1994). Moreover, in neurons lacking Rab3a, rabphilin appears to be trapped in the cell body, unable to reach its final localization on synaptic vesicles at nerve terminals. Protein instability and faster degradation were suggested as reasons to explain the reduced levels of rabphilin in the absence of Rab3A ( $\mathrm{Li}$ et al., 1994). Brains from wild-type and Rab3a KO mice of various ages were collected and processed for Western blotting and probed with $\alpha$ total rabphilin, $\alpha$ S234-P, and $\alpha$ S274-P. The developmental profiles of total rabphilin and phosphorabphilin in wild-type mice (data not shown) were equivalent to those observed in rats (Fig. 3 , open squares). We therefore matched the quantified values of total rabphilin and phosphorabphilin in wild-type mice and rats to normalize the values obtained in Rab3A knock-out animals. In Figure $3 A-C$, the closed circles represent the normalized developmental profiles of total rabphilin and phosphorabphilin in Rab3a knock-out animals. As observed in rats, in both wild-type (data not shown) and Rab3a KO mice (Fig. 3A, closed circles), total rabphilin increased steadily up to 3 weeks after birth and remained at a plateau afterwards. As expected, we detected reduced levels of total rabphilin in the Rab3a KO brains. We observed that the relative level of rabphilin in the Rab3a KO compared with wild-type animals decreased during development. In fact, at $1 \mathrm{~d}$ after birth, Rab3a KO mice still had $\sim 85 \%$ of the rabphilin amount present in wild-type animals of the same age, but this proportion decreased to $\sim 45 \%$ by postnatal day 24 , the same value detected in adult animals (data not shown). Rabphilin S234-P and S274-P showed a transient peak at approximately postnatal day 16 in both wild-type (data not shown) and in Rab3a 
A $\quad$ Rat total rabphilin

- Rab3a KO mouse total rabphilin

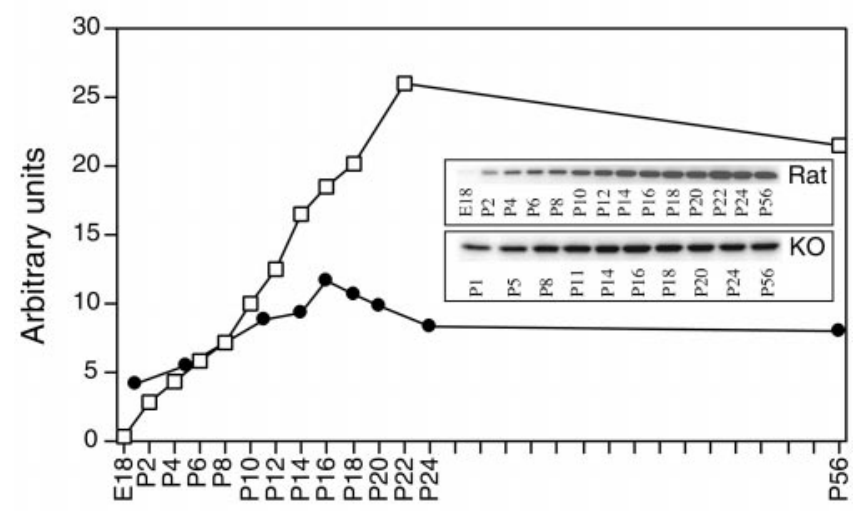

B $\quad$ Rat rabphilin S234-P

- Rab3a KO mouse rabphilin S234-P

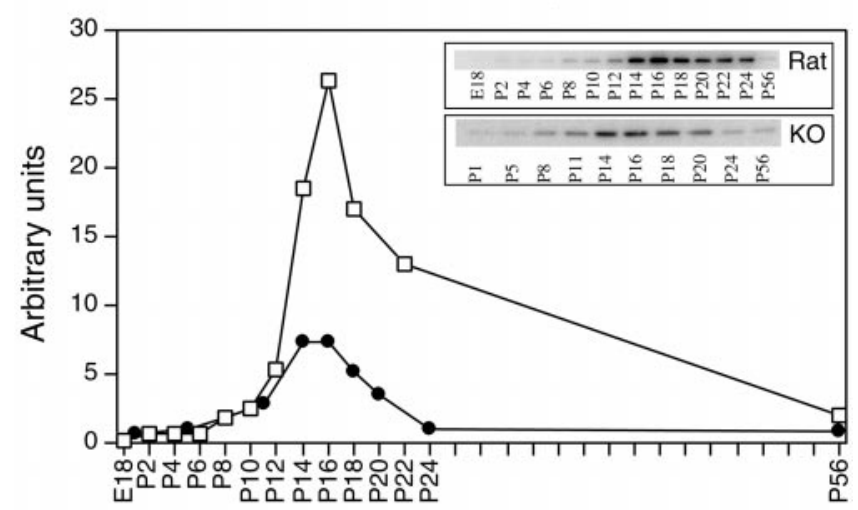

C

$\square$ Rat rabphilin S274-P

- Rab3a KO mouse rabphilin S274-P

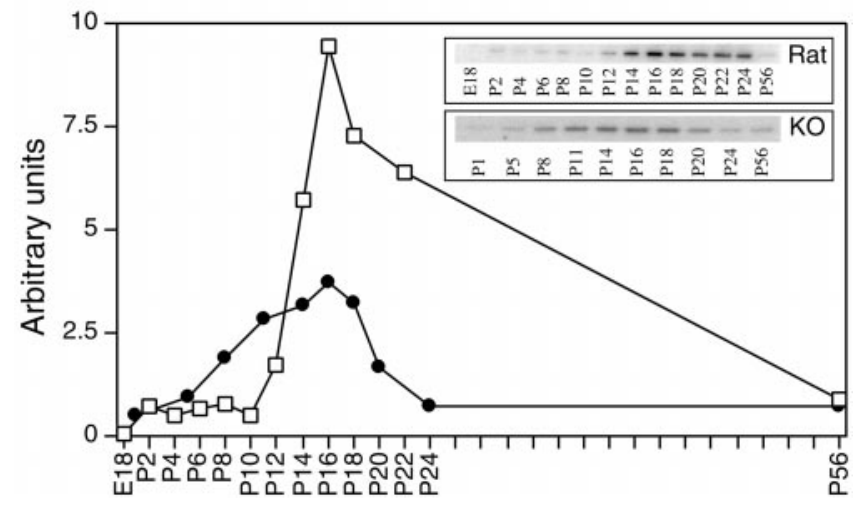

Figure 3. Phosphorabphilin is transiently upregulated during development. The brains of wild-type rats (Rat, open squares) and Rab3a knockout mice (KO, closed circles) of various ages ( $E$, embryonic; $P$, postnatal) were homogenized in the presence of phosphatase inhibitors and extracted with Triton X-100. Twenty-five micrograms of total protein from each sample was resolved by SDS-PAGE, transferred to nitrocellulose, and probed for total rabphilin $(A)$, rabphilin S234-P $(B)$, and rabphilin S274-P $(C)$. The graphs illustrate the normalized quantitative representation of the Western blots shown in the insets (the Western blots were generated in separate experiments and are not directly comparable). The developmental regulation of rabphilin and of both forms of phosphorabphilin in wild-type mice (data not shown) was equivalent to that observed in rats. We therefore matched the quantified values of total rabphilin and
KO mice (Fig. 3B, C, closed circles). The peaks of phosphorabphilin in wild-type and Rab3a knock-out mice appeared broader than in rat, possibly reflecting differences in the time course of development in the two species. Interestingly, the amplitude of the peak of phosphorabphilin in Rab3a KO animals was strongly reduced, to a level lower than that which could simply be accounted for by the reduced amount of total rabphilin. It therefore appears that although the striking transient increase in phosphorylation of rabphilin can occur in the absence of Rab3a, its magnitude is reduced in the absence of the small GTP-binding protein, suggesting that the interaction between rabphilin and Rab3a is important for its phosphorylation.

\section{Phosphorabphilin staining in cultured hippocampal neurons}

To control for the specificity of the phosphorabphilin antibodies in immunostaining, we took advantage of the Rab3A knock-out in which rabphilin is not properly targeted to synapses ( $\mathrm{Li}$ et al., 1994). We reasoned that any synaptic staining of phosphorabphilin observed in brain sections of wild-type animals should be severely reduced or abolished in sections obtained from Rab3A knock-out animals. Figure 4 shows confocal images of the cerebellar cortex taken from sagittal sections of adult wild-type (Fig. $4 A, B)$ and Rab3a knock-out animals (Fig. 4C,D). We double stained with $\alpha$ S234-P and an antibody against calbindin to label Purkinje cells (Fig. 4A,C) and with $\alpha$ S234-P and the nuclear marker Toto-3 (Fig. 4B,D). In the cerebellar cortex of wild-type mice, $\alpha \mathrm{S} 234-\mathrm{P}$ detected punctate, synaptic-like structures in the molecular layer (Fig. 4A, $M L$ ) and larger structures in the granular layer (Fig. 4B). No immunoreactivity was observed in the cerebellar cortex of Rab3a knock-out animals. Equivalent results were obtained with $\alpha \mathrm{S} 274-\mathrm{P}$ (data not shown). Additionally, preincubation of both phosphorabphilin-specific antibodies with their respective phosphopeptides (but not with the nonphosphopeptides) completely abolished the signal (data not shown). We conclude that the two phosphorabphilin antibodies are specific in immunostaining.

To assess the subcellular localization of phosphorabphilin, we cultured embryonic hippocampal neurons and performed immunocytochemistry with $\alpha \mathrm{S} 234-\mathrm{P}, \alpha \mathrm{S} 274-\mathrm{P}$, $\alpha$ total rabphilin, and known markers for synapses and axons. Mature, $14 \mathrm{~d}$ in vitro (div) hippocampal neurons with extensive axonal and dendritic trees and abundant synapses were used for staining. In double-labeling experiments in which neurons were stained for total rabphilin and the synaptic vesicle marker SV2A, we observed rabphilin in a synaptic-like pattern in the vast majority of the neurons (Fig. $5 A-C$ ). In contrast, both rabphilin S234-P (Fig. 5D-F) and rabphilin S274-P (Fig. 5G-L), although also clearly present at synapses, were detected only in a small subset of axons. Rabphilin is a synaptic protein that has been clearly localized to synaptic vesicles by electron microscopy studies (Mizoguchi et al., 1994; Li, 1996), so we expected to find phosphorabphilin colocalized with

$\leftarrow$

phosphorabphilin in wild-type mice and rats (open squares) to normalize the values obtained in Rab3A knock-out animals (closed circles). $A$, The amount of total rabphilin increases steadily during development and plateaus at approximately P22 in both rats and Rab3a knock-out mice. $B$ (rabphilin S234-P) and $C$ (rabphilin S274-P), both phosphorylated forms of rabphilin, exhibit a sharp and transient increase beginning at P8-P10 and peaking at P16, followed by a sharp decline in phosphorylation levels. This phenomenon is observed with different amplitudes in both rats (open squares) and Rab3a knock-out mice (closed circles). 

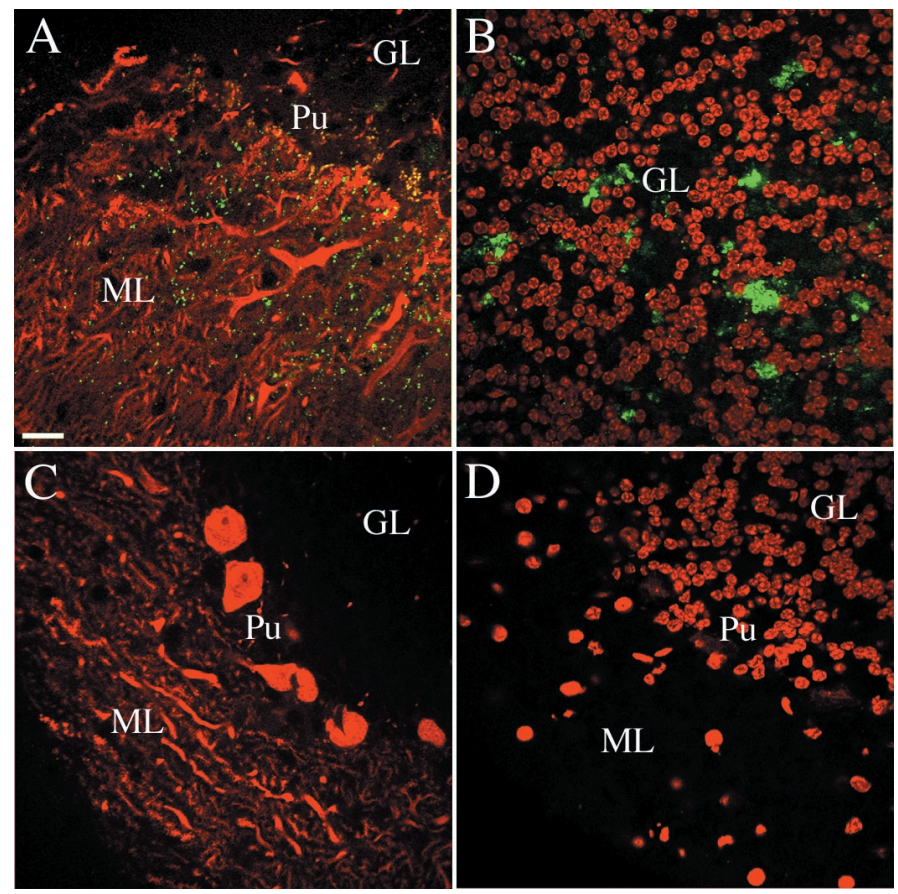

Figure 4. Specificity of the phosphorabphilin antibodies in immunostaining. In mice lacking Rab3A the overall level of rabphilin is reduced to $\sim 40 \%$ of wild type and the protein is not targeted to the synapses. We assessed the specificity of $\alpha \mathrm{S} 234-\mathrm{P}$ and $\alpha \mathrm{S} 274-\mathrm{P}$ by comparing their immunoreactivity in staining of brain sections obtained from wild-type and Rab3A knock-out animals. All of the panels are single confocal images taken from sagittal sections of the cerebellar cortex of adult wild-type or Rab3A knock-out mice. The staining for both phosphorylated forms of rabphilin was equivalent. $A, B$, Staining of sections obtained from wild-type animals; $C, D$, staining in Rab3A knock-out sections. The panels represent merged images of double labeling for rabphilin S234-P (green) with an antibody against calbindin (red in $A$ and $C$, stains Purkinje cells) or the nuclear marker Toto-3 (red in $B$ and $D$ ). In the cerebellar cortex of wild-type animals, phosphorabphilin was detected as a punctate synaptic-like staining in the molecular layer $(A)$ and staining of structures in the granular layer $(B)$. Equivalent double labeling in Rab3A knock-out sections $(C, D)$ failed to reveal staining for phosphorabphilin, confirming the specificity of the antibodies. $G L$, Granular layer; $M L$, molecular layer; $P u$, Purkinje cells. Scale bars: $A-L, 20 \mu \mathrm{m}$.

synaptic vesicle markers at synapses of cultured hippocampal neurons. Interestingly, and consistent with its nonhomogeneous distribution in the rat brain observed by Western blot analysis (Fig. 2), phosphorabphilin was detected only in a subset of synapses (Fig. 5E,H), whereas total rabphilin had a widespread synaptic distribution in these cultures (Fig. 5B). Thus, phosphorabphilin is not only more abundant in specific regions of the brain but also is present only in a subset of neurons and likely even only in a subset of synapses within a given axon. This suggests that the phosphorylation of rabphilin is a functional modification of the protein required in particular types of synapses, or synapses in a specific physiological state.

\section{Phosphorabphilin is enriched in the climbing fiber synapses of the cerebellar cortex}

We next focused our attention on the cerebellum, because abundant phosphorabphilin was detected by Western blot in this region of the brain. Confocal images were obtained at medium and high magnification from double-labeled sagittal sections of adult and postnatal day 8 rat brains.

Figure $6 A-C$ shows a double staining with Toto-3, a nuclear marker (Fig. 6A), and the antibody against total rabphilin (Fig. $6 B, C$ is the merged image). The characteristic structure of the cerebellar cortex is illustrated by the nuclear staining. Between the granular layer (GL) and the molecular layer (ML) lies the single-cell layer of Purkinje cells. Total rabphilin was strongly and homogeneously detected in the molecular layer and in structures in the granular layer; some of these structures likely represent glomeruli or rosettes, the synapses of mossy fibers onto the dendrites of granule cells. The other structures, with a characteristic staining just underneath the somas of the Purkinje cells, may be basket cell nerve terminal plexuses, or pinceaux, which are wrapped around the base and initial axon segments of the Purkinje neurons. In Figure $6 D-F$ a similar double-labeling experiment was conducted with Toto-3 (Fig. 6D) and $\alpha$ S234-P (Fig. $6 E, F$ is the merged image). As for total rabphilin, phosphorabphilin was detected in structures that are likely to be glomeruli and pinceaux in the granular layer, but the staining in the molecular layer appeared much more restricted. Figure $6 G-I$ shows a co-staining for calbindin, a marker for Purkinje cells (Fig. 6G), and $\alpha$ S234-P (Fig. 6H,I is the merged image). The phosphorabphilin staining in the molecular layer appeared punctate-like and concentrated in the portion closest to the Purkinje cell layer. The same staining pattern was obtained with $\alpha$ S274-P (Fig. 7).

We further analyzed the phosphorabphilin staining in both the granular and molecular layers at higher magnification (Fig. 7). In Figure 7, $A-F$, phosphorabphilin identified with $\alpha$ S274-P (Fig. $7 B, E$ ) is shown in a double staining with Toto-3 (Fig. $7 C$ is the merged image of $A$ and $B$ ) and the synaptic marker synaptophysin (Fig. $7 F$ is the merged image of $D$ and $E$ ). In the molecular layer, phosphorabphilin was detected in strongly labeled small synapticlike structures (Fig. 7B,C, arrows), whose identity as synapses was confirmed by their overlap with the staining for synaptophysin (Fig. 7E,F). The molecular layer contains few cells and a large number of synapses, primarily contributed by the contacts between parallel fibers and Purkinje cell dendrites. In contrast to total rabphilin, which was homogeneously present at synapses throughout the entire molecular layer (Fig. $6 A-C$ ), phosphorabphilin was clearly restricted to a subset of synapses that were strongly labeled with the anti-synaptophysin antibody. In the granular layer, phosphorabphilin was found in glomeruli or rosettes, as indicated by the double labeling with $\alpha$ S274-P (Fig. 7H) and Toto-3 (Fig. 7G,I is the merged image). This was confirmed by the colocalization of phosphorabphilin and a synaptic marker in sections stained with anti-synaptophysin (Fig. 7J) and $\alpha \mathrm{S} 234-\mathrm{P}$ (Fig. $7 K, L$ is the merged image). Interestingly, as observed for total rabphilin (Fig. 6A-C) (Li et al., 1994), some but not all the glomeruli contain phosphorabphilin (Fig. $7 J-L$, arrowheads indicate glomeruli positive for both synaptophysin and phosphorabphilin).

The presence of phosphorabphilin in a subset of synapses in the molecular layer, as opposed to the widespread distribution of total rabphilin, prompted us to further investigate the nature of these synapses. Figure $8 A-C$ is an example of a double-labeling experiment with antibodies against calbindin (Fig. $8 A$ ) and rabphilin S234-P (Fig. 8B,C is the merged image). Shown is part of the molecular layer in the cerebellar cortex, with calbindin detected in the dendrites of the Purkinje cells (Fig. 8A, the arrowheads indicate the proximal trunk of a Purkinje cell dendrite). Phosphorabphilin is found in synapses (Fig. $8 B$, arrows) that decorate the proximal aspect of the dendrite (Fig. 8C). This staining is characteristic of climbing fiber synapses, one of the two major input pathways of the cerebellum. To confirm the identity 


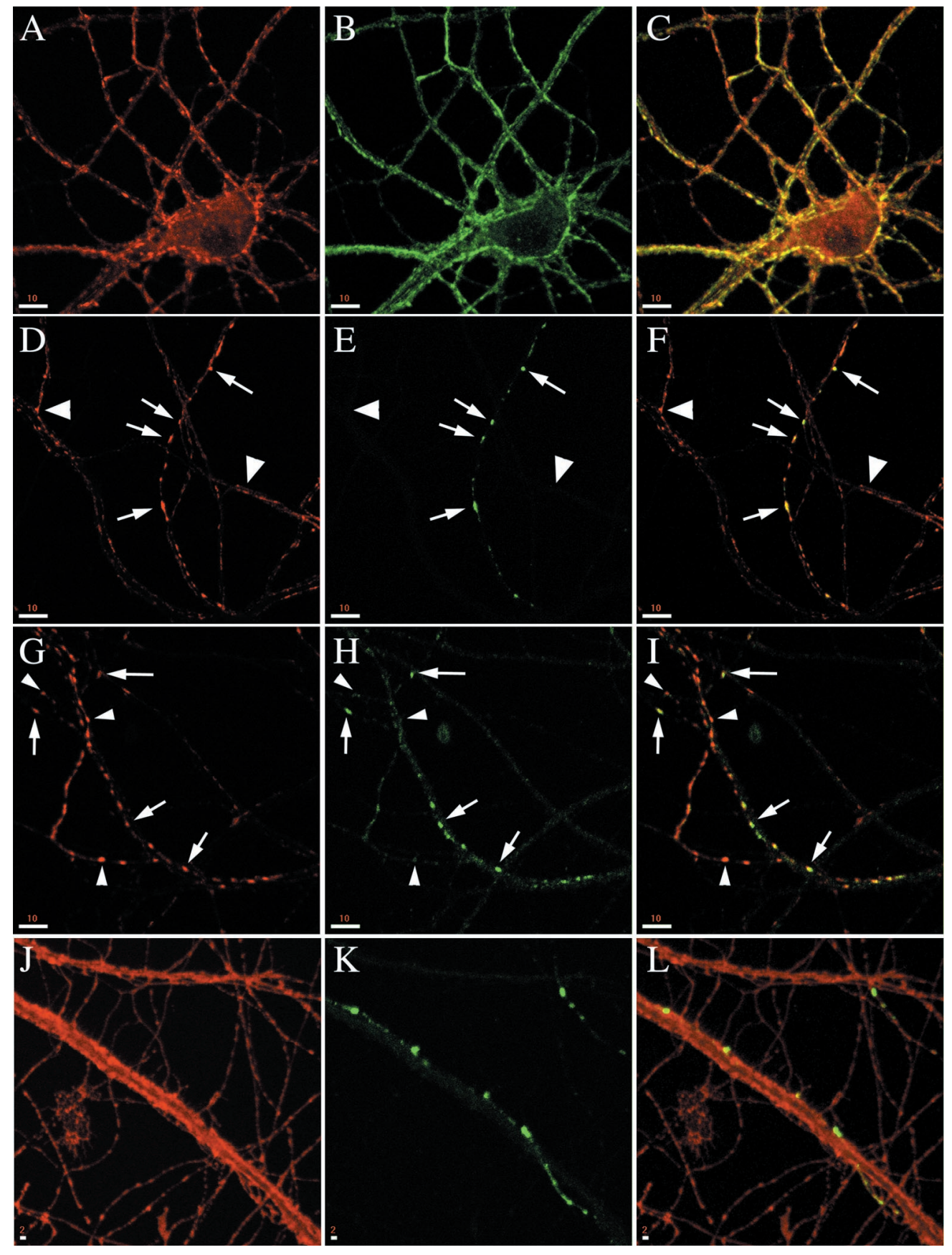

Figure 5. Phosphorylated rabphilin is localized to synapses in a subset of axons in mature cultured hippocampal neurons. Embryonic cultures of hippocampal neurons at $14 \mathrm{div}$ were fixed and stained with a panel of antibodies. $A-C$, Co-staining for the synaptic vesicle protein SV2A $(A)$ and for total rabphilin ( $B, C$ is the merged image) shows that total rabphilin is present at synapses in all neurons. $D-I$, Co-staining for SV2A $(D, G)$ and rabphilin S234-P $(E)$ or rabphilin S274-P $(H)$ reveals that phosphorylated rabphilin is also present at synapses (arrows in $D-I$ ), but only in a small subset of axons. Large arrowheads in $D-F$ point to axons devoid of rabphilin S234-P staining, and small arrowheads in $G-I$ point to SV2A-labeled synapses that do not have detectable rabphilin S274-P. F and $I$ are the respective merged images. $J-L, C o$-staining for the plasma membrane protein syntaxin1A $(J)$ and rabphilin S274-P $(K, L$ is the merged image) shows the synaptic localization of phosphorylated rabphilin in an axon that runs along and makes contacts with a dendrite. Scale bars: $A-I, 10 \mu \mathrm{m} ; J-L, 2 \mu \mathrm{m}$. of these synapses, we took advantage of their particular developmental regulation. Early in development, climbing fibers establish synapses only on the soma of Purkinje cells. Later, as the Purkinje cells mature and extend their dendrites into the molecular layer, these synapses disappear and new synapses are formed, mostly on the proximal part of the dendritic tree. We stained rat brain sagittal sections from postnatal day 8 animals. In the experiment shown in Figure $8 D-F$, we used Toto-3 to stain nuclei (Fig. $8 D$ ) and detected phosphorabphilin with $\alpha$ S274-P (Fig. $8 E, F$ is the merged image). Purkinje cells, identified by their large nucleus in Figure $8 D(\mathrm{Pu})$, lie at the boundary between the granular and molecular layers. Their cell body was decorated with synapses positive for phosphorabphilin (Fig. $8 E, F$ ). In Figure $8 G-I$, rabphilin S274-P (Fig. $8 H$ ) was detected together with calbindin (Fig. $8 G, I$ is the merged image). Intense synaptic-like phosphorabphi- lin staining was again observed on the soma of the Purkinje cells, but no staining was observed on their short immature dendrites. The synaptic nature of the phosphorabphilin staining was confirmed in the double-staining experiment of Figure $8 \mathrm{~J}-\mathrm{L}$. The staining generated by $\alpha$ S274-P (Fig. $8 K$ ) overlapped with some of the synapses labeled with anti-synaptophysin (Fig. 8J,L is the merged image). As observed above, only synapses on the Purkinje cell bodies $(\mathrm{Pu})$ contained phosphorabphilin (Fig. 8J-L, arrows), whereas other synapses in both the granular and molecular layers were phosphorabphilin-negative (Fig. 8J,L, arrowheads). Therefore, the presence of phosphorylated rabphilin is selective for the climbing fiber synapses, whereas total rabphilin is also found in the numerous parallel fiber synapses, the other excitatory input onto the Purkinje cell dendrites in the molecular layer. This is consistent with what we observed in cultured neurons and dem- 
Figure 6. Phosphorabphilin is present in the rat cerebellar cortex. All of the panels are single confocal images taken from sagittal sections of the cerebellar cortex of adult rats. The staining for both phosphorylated forms of rabphilin was equivalent. $A-C$, Double staining with Toto-3 ( $A$, stains the nuclei) and the $\alpha$ total rabphilin antibody $(B, C$ is the merged image) shows that total rabphilin is homogeneously expressed in the molecular layer and in some structures, likely glomeruli and pinceaux, in the granular layer. $D-F$, Double labeling with Toto-3 $(D)$ and $\alpha$ S234-P $(E, F$ is the merged image) results in a similar staining of structures in the granular layer but a more restricted staining in the molecular layer for phosphorabphilin compared with total rabphilin. $G-I$, The nonhomogeneous presence of phosphorabphilin in the molecular layer is further confirmed in a co-staining for calbindin $(G$, stains the Purkinje cells) and rabphilin S234-P $(H, I$ is the merged image). The staining appears punctate and concentrated in the portion of the molecular layer closest to the Purkinje cell layer. Scale bars: $A-F, 200$ $\mu \mathrm{m} ; G-I, 100 \mu \mathrm{m}$.
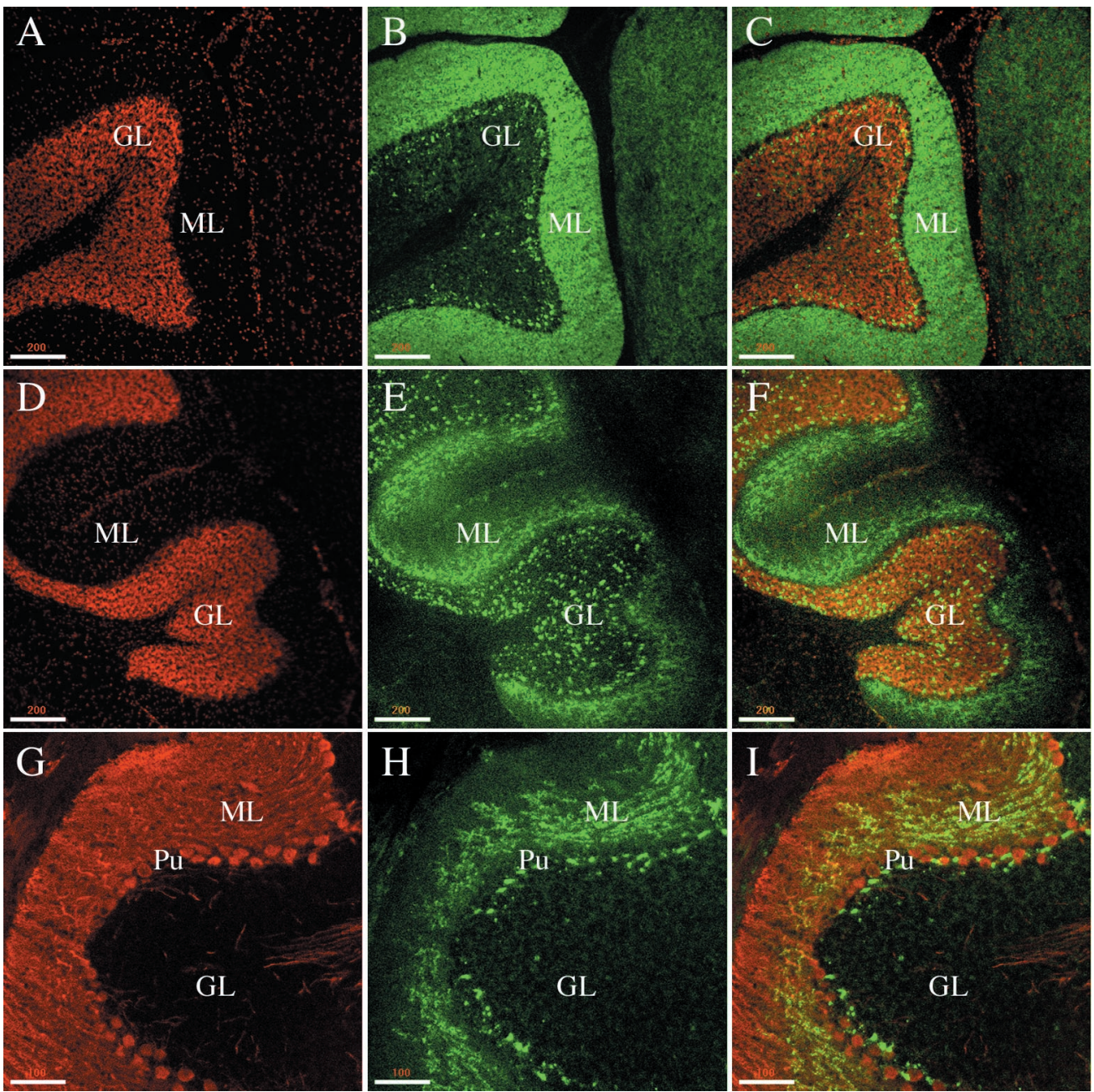

onstrates that the phosphorylation of rabphilin is physiologically regulated in a specific subset of synapses.

\section{DISCUSSION}

Although the basic core machinery for the release of neurotransmitters is likely shared by most neurons, its regulation by modulatory mechanisms determines in part the strength of individual synapses and therefore contributes to the process of synaptic plasticity. One such modulatory mechanism is protein phosphorylation. Protein kinases and phosphatases have been implicated in regulating synaptic plasticity (for review, see Schulman, 1995; Tokuda and Hatase, 1998), and numerous synaptic proteins have been reported as potential targets for phosphorylation (for review, see Turner et al., 1999). Many studies on phosphoproteins have been performed in vitro with recombinant proteins and purified kinases. In vivo studies have generally relied on phosphoamino acid analysis, phosphopeptide mapping, and metabolic labeling with inorganic ${ }^{32} \mathrm{P}$ followed by immunoprecipitation of the protein under study. These approaches do not allow accurate localization of the protein of interest at a subcellular level or in specific synapses within the brain and are not easily amenable to developmental studies. To address these issues, we have generated phosphospecific antibodies, reagents that detect a protein only when it is phosphorylated at a specific residue. In this report, we describe our work with two phosphospecific antibodies directed against serine-234 and serine-274 of rabphilin, a synaptic protein that interacts with the small GTPase Rab3a and whose function is still controversial.

We show that rabphilin is phosphorylated in vivo under basal conditions at both serine-234 and serine-274. Western blot analysis revealed that although rabphilin is quite homogeneously expressed, both forms of phosphorabphilin are particularly abundant in the cerebellum, midbrain, and medulla. We further investigated the specific distribution of phosphorabphilin by immunocytochemistry in cultured hippocampal neurons and immunohistochemistry on rat brain sections. In neurons, although there was a widespread synaptic presence of rabphilin, both rabphilin S234-P and rabphilin S274-P were detected only in a small subset of synapses. In the cerebellum, rabphilin appeared localized to all synapses of the molecular layer, but both forms of phosphorabphilin were found exclusively in the climbing fiber synapses. Although it has been shown previously that not all synapses contain rabphilin (Li et al., 1994; Schluter et al., 1999; Von Kriegstein et al., 1999), we show here that even within the synapses that express the protein, only in a subset is rabphilin modified by phosphorylation. In the cerebellum, Purkinje cells constitute the only output of information. The dendrite of a single Purkinje cell, with 150,000-175,000 excitatory synaptic connections, receives more synaptic inputs than any other neuron in the brain (Ito, 1984). The vast majority of these synapses are contributed by parallel fibers, the axons of granule cells. In contrast, the 

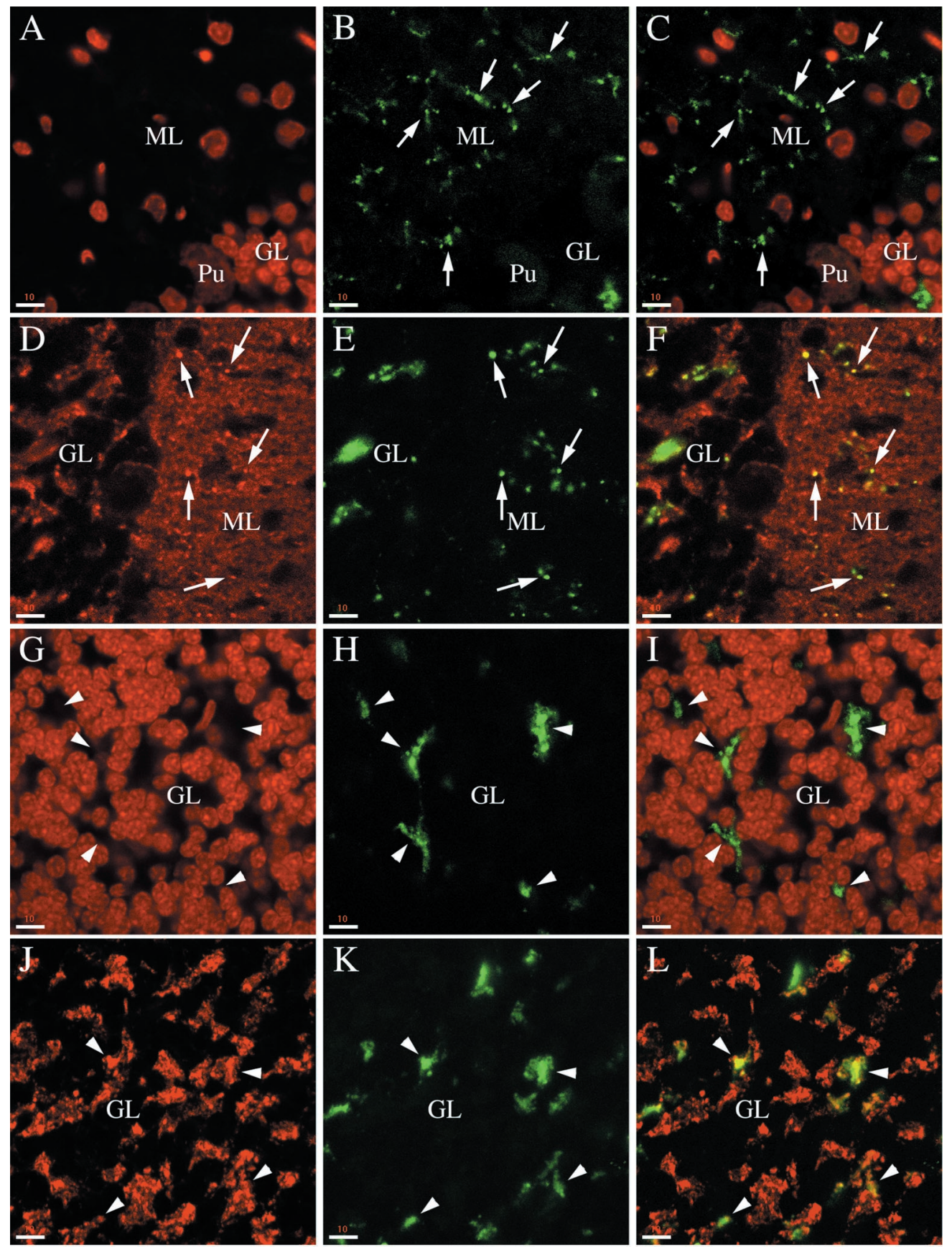

Figure 7. Phosphorabphilin is present in a subset of synapses in the molecular layer and in the granular layer. All of the panels are single $(A-F)$ or collapsed $(G-L)$ serial confocal images taken from sagittal sections of the cerebellar cortex of adult rats. The staining for both phosphorylated forms of rabphilin was equivalent. $A-C$, High magnification images of double staining for nuclei with Toto-3 $(A)$ and phosphorabphilin with $\alpha \operatorname{Ser} 274-\mathrm{P}(B, C$ is the merged image). In the molecular layer intense staining for phosphorabphilin is observed in small synaptic-like structures (some of which are indicated by the arrows; $P u$ marks the large nucleus of a Purkinje cell at the boundary between the molecular and granular layers). $D-F$, The synaptic identity of the phosphorabphilin staining in the molecular layer was confirmed by a double staining for the synaptic vesicle protein synaptophysin $(D)$ and for rabphilin S234-P ( $E, F$ is the merged image). The molecular layer is packed with synapses, for the most part contributed by the parallel fibers, the axons of the granule cells. The double staining shows clear colocalization of the phosphorabphilin-containing structures with a small subset of particularly brightly stained synapses (some of which are indicated by arrows), whereas no phosphorabphilin is detected in the rest of the synapses in the molecular layer. $G-L$, The phosphorabphilin staining in the granular layer was further characterized at high magnification with double staining with the $\alpha \mathrm{S} 274-\mathrm{P} \quad(H)$ or $\alpha$ S234-P $(K)$ antibodies together with staining for nuclei with Toto-3 $(G)$ or synaptic vesicles with $\alpha$-synaptophysin antibody $(J) . I$ is the merged image of $G$ and $H$, and $L$ is the merged image of $J$ and $K$. In the granular layer, phosphorabphilin is detected in areas free of cell bodies of the densely packed granule cells (arrowheads in $G-I$ ). This is where the glomeruli are located, as confirmed by the colocalization with synaptophysin (arrowheads in $J-L$ ). Note that only a subset of glomeruli stains positive for phosphorabphilin. Scale bars: $A-L, 10 \mu \mathrm{m}$. other source of excitatory input to each Purkinje cell is provided by some 300 synapses coming from a single climbing fiber, an axonal projection from the inferior olive (Ito, 1984). Parallel and climbing fibers contact separate, nonoverlapping regions of the Purkinje cell dendrite. Climbing fiber synapses are established on the thick, smooth part of the dendrite, whereas the parallel fiber synapses are made exclusively on the spiny branchelets (the small spine-covered tertiary dendrites of the Purkinje cell) (Palay and Chan-Palay, 1974). We have shown that under basal conditions, rabphilin is present at both types of synapses in the cerebellar cortex, but that phosphorabphilin is detected only in the climbing fibers. Phosphorabphilin is therefore present at synapses that exert a critical effect on in-flow of cerebellar information, suggesting that it may regulate aspects of the physiological state of these particular synapses.
Another potential role for phosphorabphilin was revealed by a survey of its developmental profile. Rabphilin levels increased steadily after birth and reached a plateau after $\sim 3$ weeks, a pattern followed by several synaptic proteins (Foletti et al., 2000). In contrast, both rabphilin S234-P and rabphilin S274-P levels showed a sharp increase that started at postnatal day 10-12, peaked at day 16, and declined afterwards. The amplitude of this phenomenon was decreased but not abolished in mice lacking Rab3a. Intriguingly, the peak of phosphorabphilin level at postnatal day 16 exactly falls into the critical period for activitydependent synapse elimination in the cerebellum. Refinement of redundant connections formed at earlier developmental stages progresses through synapse elimination, one of the final steps in neuronal circuit formation (Lohof et al., 1996). The synapses between climbing fibers and Purkinje cells undergo such a prun- 
Figure 8. Phosphorabphilin is enriched in climbing fiber synapses. All of the panels are single confocal images taken from sagittal sections of the cerebellar cortex of adult rats $(A-C)$ or postnatal day 8 animals $(D-L)$. The staining for both phosphorylated forms of rabphilin was equivalent. $A-C$, Double staining for calbindin $(A$, stains the Purkinje cell dendrites) and rabphilin S234-P $(B)$ in the molecular layer. The merged image $(C)$ reveals that the phosphorabphilin-containing synapses (arrows) decorate the proximal aspect of the Purkinje cell dendrites (arrowheads). This staining is characteristic for climbing fiber synapses. To confirm the identity of these synapses, we double-stained brain sections of postnatal day 8 animals. At this age the climbing fibers make synapses exclusively on the cell body of the Purkinje cells, later in development these synapses disappear and new synapses are formed climbing up the Purkinje cell dendrites. $D-F$, Double staining with the nuclear marker Toto-3 ( $D$, note the very large nuclei of the Purkinje cells) and with the $\alpha$ S274-P antibody $(E)$. As shown in the merged image $(F)$, phosphorabphilin staining is restricted to the cell body of the Purkinje cells. $G-I$, The double staining for calbindin to stain Purkinje cells $(G)$ and for rabphilin S274-P $(H)$ confirms the presence of phosphorabphilin-containing synapses on the cell bodies but not on the growing dendrites of the Purkinje cells $(I) . J-L$, The synaptic nature of the staining for phosphorylated rabphilin is further corroborated by a double labeling with antibodies for the synaptic vesicle protein synaptophysin $(J)$ and for rabphilin S274-P ( $K, L$ is the merged image). The phosphorabphilin immunoreactivity on the cell bodies of Purkinje cells colocalizes with the synaptic staining of synaptophysin (arrows), but other synapses in the molecular and granular layer (some of which are indicated by the arrowheads) are not stained for phosphorabphilin. Scale bars: $A-L, 10 \mu \mathrm{m}$
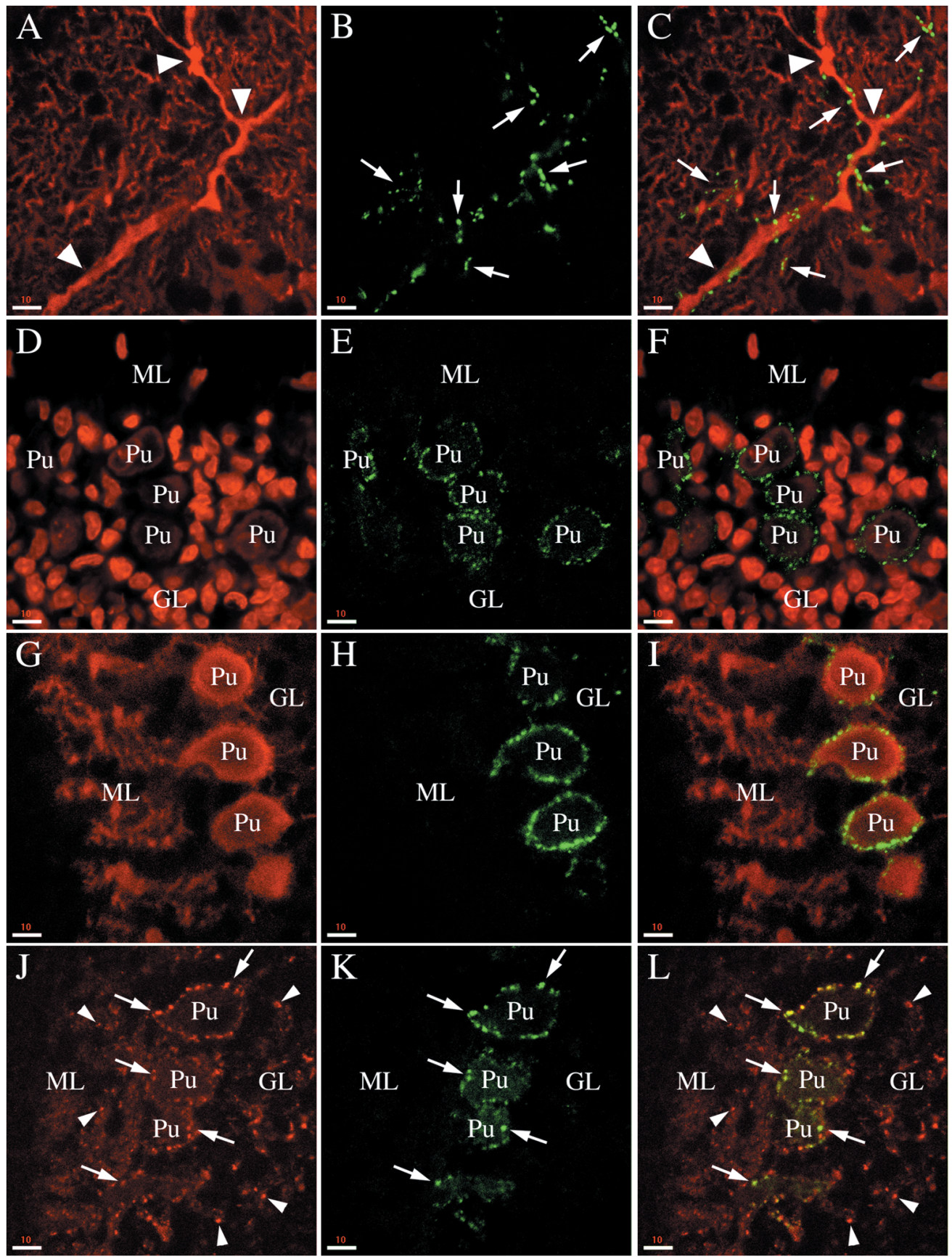

ing mechanism. In early postnatal days, multiple climbing fibers contact individual Purkinje cells. Elimination of supernumerary climbing fibers reduces their number to a strict one-to-one relationship with each Purkinje cell (Changeaux et al., 1973; Crepel, 1982; Ito, 1984; Lohof et al., 1996). This process progresses over three distinct phases, the last of which depends on NMDA receptor-mediated activity and occurs within a narrow timewindow between postnatal day 15 and 16 (Rabacchi et al., 1992; Kakizawa et al., 2000). This is the time during development when we observe peak levels of phosphorabphilin in the brain, and immunohistochemistry shows abundant phosphorabphilin in climbing fiber synapses. It is therefore tempting to speculate that phosphorylation of rabphilin within climbing fiber synapses may be involved in the events responsible for synapse elimination. In the analysis of rabphilin knock-out mice, the synaptic architecture of the brain, including the cerebellum, appeared normal (Schluter et al., 1999). Because climbing fiber synapses are massively outnumbered by parallel fiber synapses, it is not surprising that the analysis of the synaptic staining in the cerebellar cortex did not reveal any aberration in the organization of the climbing fibers. It would be interesting to test, electrophysiologically, if there is evidence for supernumerary climbing fibers contacting each Purkinje cell in the cerebellum of rabphilin knock-out animals.

Taken together, these results suggest that the phosphorylation of rabphilin is a modulatory mechanism to regulate the function of the protein to respond to particular physiological needs during synaptogenesis and synaptic activity in a cell- and synapsespecific manner.

Rabphilin has a tripartite domain structure. The N-terminal portion of the protein contains a $\mathrm{Zn}^{2+}$-finger and is responsible 
for the binding to Rab3a (Yamaguchi et al., 1993; Li et al., 1994; Ostermeier and Brunger, 1999). The C-terminal region of rabphilin is comprised of two $\mathrm{C} 2$ domains that have been shown to bind $\mathrm{Ca}^{2+}$ and phospholipids (Yamaguchi et al., 1993; Oishi et al., 1996; Chung et al., 1998; Ubach et al., 1999). The two phosphorylation sites are in the middle of the molecule between the N-terminal domain that binds Rab3a and connects rabphilin to the synaptic vesicle, and the $\mathrm{C}$-terminal region with the two $\mathrm{C} 2$ domains that bind phospholipids in $\mathrm{Ca}^{2+}$-dependent manner. It therefore seems that they are optimally located to modulate the activity of the protein.

The function of rabphilin remains controversial. A rabphilin knock-out study showed that rabphilin is not essential, in fact the knock-out animals are viable and fertile without obvious impairments in synaptic transmission (Schluter et al., 1999). Yet, evidence from overexpression and microinjection experiments strongly implicates rabphilin in the exocytotic process. Presynaptic microinjection of full-length rabphilin or its $\mathrm{N}$ - and $\mathrm{C}$-terminal domains inhibited neurotransmitter release in squid nerve terminals (Burns et al., 1998). Similarly, microinjection of the $\mathrm{N}$ - and C-terminal fragments of rabphilin into mouse metaphase II eggs inhibited cortical granule exocytosis at fertilization (Masumoto et al., 1996). Furthermore, overexpression of full-length rabphilin or various fragments and mutants of the protein in PC12 cells, chromaffin cells, and pancreatic $\beta$ cells have been shown to stimulate or inhibit exocytosis, respectively (Chung et al., 1995; Komuro et al., 1996; Arribas et al., 1997; Joberty et al., 1999).

As mentioned above, rabphilin is not present at all synapses. Of particular interest is its absence from ribbon synapses in the outer plexiform layer of the retina in rodents (Von Kriegstein et al., 1999). The presynaptic aspect of these terminals contains electron-dense projections (ribbons) at the plasma membrane. Ribbons are thought to bind synaptic vesicles and guide them to the active zone for fusion, a process that accelerates the delivery of vesicles for continuous exocytosis. It is possible that the absence of rabphilin (and synapsin, but not the other synaptic proteins tested) from these synapses provides insight into its function. Synapsin is one of the best-characterized synaptic phosphoproteins and its role in the release of synaptic vesicles from the reserve pool is regulated by phosphorylation (Greengard et al., 1993; Hosaka et al., 1999). At rest, synaptic vesicles in the reserve pool are thought to be anchored to the cytoskeleton through dephosphorylated synapsin. After an action potential and stimulation of protein kinases (CaMKII and PKA), synapsin becomes phosphorylated, changes its conformation and disengages synaptic vesicles from the cytoskeleton. By analogy, rabphilin bound to synaptic vesicles via Rab3a may be involved in synaptic vesicle mobilization and targeting from the reserve pool to the active zone. This role could be bypassed in ribbon synapses, where the ribbon itself constitutes the physical link between the pool of synaptic vesicles and the site of exocytosis. Although synapsin may exert its role in most if not all synapses, we propose that phosphorylation of rabphilin modulates its activity, possibly in the mobilization and targeting of synaptic vesicles, in a specific subset of synapses or under particular physiological conditions.

\section{REFERENCES}

Arribas M, Regazzi R, Garcia E, Wollheim CB, De Camilli P (1997) The stimulatory effect of rabphilin $3 \mathrm{a}$ on regulated exocytosis from insulin-secreting cells does not require an association-dissociation cycle with membranes mediated by Rab 3. Eur J Cell Biol 74:209-216.
Banker GA, Cowan MW (1977) Rat hippocampal neurons in dispersed cell culture. Brain Res 126:397-425.

Bock JB, Matern HT, Peden AA, Scheller RH (2001) A genomic perspective on membrane compartment organization. Nature 409:839-841.

Burns ME, Sasaki T, Takai Y, Augustine GJ (1998) Rabphilin-3A: a multifunctional regulator of synaptic vesicle traffic. J Gen Physiol 111:243-255.

Changeaux JP, Courrege P, Danchin A (1973) A theory of epigenesis of neuronal networks by selective stabilization of synapses. Proc Natl Acad Sci USA 70:2974-2978.

Chung SH, Takai Y, Holz RW (1995) Evidence that the Rab3a-binding protein, rabphilin3a, enhances regulated secretion. Studies in adrenal chromaffin cells. J Biol Chem 270:16714-16718.

Chung SH, Song WJ, Kim K, Bednarski JJ, Chen J, Prestwich GD, Holz RW (1998) The C2 domains of Rabphilin3A specifically bind phosphatidylinositol 4,5-bisphosphate containing vesicles in a $\mathrm{Ca}^{2+}$. dependent manner. In vitro characteristics and possible significance. J Biol Chem 273:10240-10248.

Crepel F (1982) Regression of functional synapses in the immature mammalian cerebellum. Trends Neurosci 5:266-269.

Foletti DL, Lin R, Finley MAF, Scheller RH (2000) Phosphorylated syntaxin 1 is localized to discrete domains along a subset of axons. J Neurosci 20:4535-4544.

Fykse EM (1998) Depolarization of cerebellar granule cells increases phosphorylation of rabphilin-3A. J Neurochem 71:1661-1669.

Fykse EM, Li C, Südhof TC (1995) Phosphorylation of rabphilin-3A by $\mathrm{Ca}^{2+} /$ calmodulin- and cAMP-dependent protein kinases in vitro. J Neurosci 15:2385-2395.

Geppert M, Bolshakov VY, Siegelbaum SA, Takei K, De Camilli P, Hammer RE, Südhof TC (1994) The role of Rab3a in neurotransmitter release. Nature 369:493-497.

Greengard P, Valtorta F, Czernik AJ, Benfanti F (1993) Synaptic vesicle phosphoproteins and regulation of synaptic function. Science 259:780-785.

Hazuka CD, Foletti DL, Hsu SC, Kee Y, Hopf W, Scheller RH (1999) The Sec6/8 complex is located at neurite outgrowth and axonal synapse-assembly domains. J Neurosci 19:1324-1334.

Hosaka M, Hammer RE, Südhof TC (1999) A phospho-switch controls the dynamic association of synapsins with synaptic vesicles. Neuron 24:377-387.

Ito M (1984) The cerebellum and neural control. New York: Raven.

Jahn R, Südhof TC (1999) Membrane fusion and exocytosis. Annu Rev Biochem 68:863-911.

Joberty G, Stabila PF, Coppola T, Macara IG, Regazzi R (1999) High affinity Rab3 binding is dispensable for Rabphilin-dependent potentiation of stimulated secretion. J Cell Sci 112:3579-3587.

Kakizawa S, Yamasaki M, Watanabe M, Kano M (2000) Critical period for activity-dependent synapse elimination in developing cerebellum. J Neurosci 20:4954-4961.

Kato M, Sasaki T, Ohya T, Nakanishi H, Nishioka H, Imamura M, Takai Y (1996) Physical and functional interaction of rabphilin-3A with alpha-actinin. J Biol Chem 271:31775-31778.

Komuro R, Sasaki T, Orita S, Maeda M, Takai Y (1996) Involvement of rabphilin-3A in $\mathrm{Ca} 2+$-dependent exocytosis from PC12 cells. Biochem Biophys Res Commun 219:435-440.

Li C, Takei K, Geppert M, Daniell L, Stenius K, Chapman ER, Jahn R, De Camilli P, Südhof TC (1994) Synaptic targeting of rabphilin-3A, a synaptic vesicle $\mathrm{Ca}^{2+}$ /phospholipid-binding protein, depends on Rab3a/3C. Neuron 13:885-898.

Li JY (1996) Rabphilin-3A is transported with fast anterograde axonal transport and associated with synaptic vesicles. Synapse 23:79-88.

Lin RC, Scheller RH (2000) Mechanisms of synaptic vesicle exocytosis. Annu Rev Cell Dev Biol 16:19-49.

Lohof AM, Delhaye-Bouchaud N, Mariani J (1996) Synapse elimination in the central nervous system: functional significance and cellular mechanisms. Rev Neurosci 7:85-101.

Lonart G, Südhof TC (1998) Region-specific phosphorylation of rabphilin in mossy fiber nerve terminals of the hippocampus. J Neurosci 18:634-640.

Masumoto N, Sasaki T, Tahara M, Mammoto A, Ikebuchi Y, Tasaka K, Tokunaga M, Takai Y, Miyake A (1996) Involvement of Rabphilin-3A in cortical granule exocytosis in mouse eggs. J Cell Biol 135:1741-1747.

Miyazaki M, Shirataki H, Kohno H, Kaibuchi K, Tsugita A, Takai Y (1994) Identification as beta-adducin of a protein interacting with rabphilin-3A in the presence of $\mathrm{Ca}^{2+}$ and phosphatidylserine. Biochem Biophys Res Commun 205:460-466.

Mizoguchi A, Yano Y, Hamaguchi H, Yanagida H, Ide C, Zahraoui A, Shirataki H, Sasaki T, Takai Y (1994) Localization of Rabphilin-3A on the synaptic vesicle. Biochem Biophys Res Commun 202:1235-1243.

Oishi H, Sasaki T, Takai Y (1996) Interaction of both the C2A and C2B domains of rabphilin3 with $\mathrm{Ca}^{2+}$ and phospholipid. Biochem Biophys Res Commun 229:498-503. 
Ohya T, Sasaki T, Kato M, Takai Y (1998) Involvement of Rabphilin3 in endocytosis through interaction with Rabaptin5. J Biol Chem 273:613-617.

Ostermeier C, Brunger AT (1999) Structural basis of Rab effector specificity: crystal structure of the small G protein Rab3a complexed with the effector domain of rabphilin-3A. Cell 1999 96:363-374.

Palay SL, Chan-Palay V (1974) Cerebellar cortex. New York: Springer. Rabacchi S, Bailly Y, Delhaye-Bouchaud N, Mariani J (1992) Involvement of the $N$-methyl-D-aspartate (NMDA) receptor in synapse elimination during cerebellar development. Science 256:1823-1825.

Schluter OM, Schnell E, Verhage M, Tzonopoulos T, Nicoll RA, Janz R, Malenka RC, Geppert M, Südhof TC (1999) Rabphilin knock-out mice reveal that rabphilin is not required for rab3 function in regulating neurotransmitter release. J Neurosci 19:5834-5846.

Schulman H (1995) Protein phosphorylation in neuronal plasticity and gene expression. Curr Opin Neurobiol 5:375-381.

Shirataki H, Kaibuchi K, Sakoda T, Kishida S, Yamaguchi T, Wada K, Miyazaki M, Takai Y (1993) Rabphilin-3A, a putative target protein for smg p25A/rab3A p25 small GTP-binding protein related to synaptotagmin. Mol Cell Biol 13:2061-2068.

Stahl B, Chou JH, Li C, Südhof TC, Jahn R (1996) Rab3 reversibly recruits rabphilin to synaptic vesicles by a mechanism analogous to raf recruitment by ras. EMBO J 15:1799-1809.

Tokuda M, Hatase O (1998) Regulation of neuronal plasticity in the central nervous system by phosphorylation and dephosphorylation. Mol Neurobiol 17:137-156.

Turner KM, Burgoyne RD, Morgan A (1999) Protein phosphorylation and the regulation of synaptic membrane traffic. Trends Neurosci 22:459-464.

Ubach J, Garcia J, Nittler MP, Südhof TC, Rizo J (1999) Structure of the Janus-faced C2B domain of rabphilin. Nat Cell Biol 1:106-112.

Von Kriegstein K, Schmitz F, Link E, Südhof TC (1999) Distribution of synaptic vesicle proteins in the mammalian retina identifies obligatory and facultative components of ribbon synapses. Eur J Neurosci $11: 1335-1348$.

Yamaguchi T, Shirataki H, Kishida S, Miyazaki M, Nishikawa J, Wada K, Numata S, Kaibuchi K, Takai Y (1993) Two functionally different domains of rabphilin-3A, Rab3A p25/smg p25A-binding and phospholipid- and $\mathrm{Ca}(2+)$-binding domains. J Biol Chem 268:27164-27170.

Yang B, Gonzalez L, Prekeris R, Steegmaier M, Advani RJ, Scheller RH (1999) SNARE interactions are not selective: implications for membrane fusion specificity. J Biol Chem 274:5649-5653. 